\title{
Formation of the value system of pedagogical universities' students during their study
}

\author{
Tatyana Ledovskaya ${ }^{1}$, Nikita Solynin ${ }^{1}$, Larisa Danilova $^{2}$, and Alexandr Khodyrev $^{2}$ \\ ${ }^{1}$ Yaroslavl State Pedagogical University, department of pedagogical psychology, 150000 \\ Respublikanskaya street, 108, Russian Federation \\ ${ }^{2}$ Yaroslavl State Pedagogical University, department of theory and history of pedagogic, 150000 \\ Respublikanskaya street, 108, Russian Federation
}

\begin{abstract}
The authors rely on the theoretical position that value orientations should determine the meaning, validity and direction of pedagogical transformations, because values serve as basic norms and principles shaping consciousness and behaviour of people in society. The aim of the study is to determine features of formation of pedagogical University students' value system during their period of higher professional education. Authors found that in the first year of training at a pedagogical University, there is no regularity in the prevalence of "polarity" in value orientations, i.e. there are both altruistic and selfish values. In the second year, there is more focus on the "internal" orientation of the values, on their egoistic tendencies. In the third year there is a certain balance in individual and social direction of the values and value orientations. In the fourth year, there is a "public direction " of the students' values, manifested in greater democratization, collectivization, in humanization of life ideals, i.e. in the fourth year under influence of industrial practices and studying professional disciplines professional identity of pedagogical universities students begins to shape. It is proved that the system of values in case of pedagogical university students develops during the period of their higher professional education.
\end{abstract}

\section{Abstract}

At present, the prospects of using the axiological approach in science are actively discussed in the psychological and educational literature.

Implementation of the axiological approach in the teacher training system is to help a person "move from the object space into the space of human activity, life's meanings and values" (V.P. Zinchenko), "into the space of human spirituality" (V.V. Gorshkova). The modern education system is characterized by constant changes like development of Federal State Educational Standards, partial implementation of distance learning forms in education, improvement of the assessment of student learning outcomes, etc. The validity and aims of these educational transformations should be based on the modern trends in implementation of the axiological approach in education, where value guidelines should determine all the meaning and content of education $[1 ; 2]$. 
The problem of studying the values of teacher education appears already at the stage of working with terminology. Currently, there are many surveys dedicated to values and value orientations (like researches by B.S. Alisheva [3], A.N. Kuteinikova, E.I. Ogareva [4], E.A. Omelchenko, G.S. Chesnokova, R.O. Agavelyan [5] and others). Some authors consider these terms as synonyms, while the others understand them as different formations. Besides, there is no common comprehension of the component composition of the teacher training values (internal and external). One admits also some nebulosity in formulation of those values, which does not allow the choice of methodological tools for their study.

Scholars from Western European and North American countries have focused their attention on one large aspect of educational axiology, on the theme of teacher's values. Since the last third of the twentieth century, scientists have been actively studying the correspondence of value orientations and teachers' characteristics to national or educational values. As a rule, the topic is associated with the problem of value education in schools ( $R$. Dwyer [6]). However, the issues of the teacher's values deal with the already formed value orientations and concern the practising teachers, but not the future ones.

The study of post-traditional values is the subject in the research of R. Inglehart, the author of the sociological theory of post-materialism. He highlights such young generations' values as high self-esteem, self-confidence, mobility, flexibility, easiness of perception of the new, frequent change of place and environment, focus on rapid social growth [7]. British researchers (G. Czerniawski and others) experimentally proved a huge role of school childhood in forming the teacher's values, they established that in high schools there is no longer formation, but already development of the views accumulated by students at school and a purposeful focus on the experience confirming such views [8].

The theoretical analysis of the problem allowed us to assume that the system of pedagogical values is developed in students precisely during their study at the university [9], since in adolescence, due to professional and personal self-determination, the formation of personality's traits takes place which contribute to entering the profession, the level of reflection and reflexivity increases, adequate motivation is formed $[1 ; 10]$.

\section{Methods}

To study the development of students' values during their higher professional education, we used the following psychodiagnostic methods:

1. "Methodology for diagnosing the structure of values" by B.S. Alishev [11]. It includes diagnostics of 3 value spaces: a) primary functional values indicated by such fundamental concepts as benefit, truth, beauty, power (strength), justice, freedom, goodness; b) values as spheres of life, including family, love, friendship, rest, work, social life, taking care of one's own health; c) values as life goals, which include the main driving forces of a person's activity and his aspirations: peace, wealth, harmony in relationships, status, diversity in life, self-development, dedication, as well as complex scales of values (complex objects).

2. Methods of diagnosing the value orientation of the individual in the continuum "I not I" (B.S. Alishev, E.R. Sageeva). The value orientation in the continuum "I - not I" is defined by the authors as a relatively independent personality's characteristic that has an attitudinal nature, which affects the formation of a certain self-attitude and other personal characteristics of the self-concept, it also has certain connections with various social attitudes and affects the behavior of the individual with oneself and others.

3. The comprehensive methods for studying basic social attitudes of a personality (B.S. Alishev, G.I. Kashapova, E.R. Sageeva). The methods are focused on measuring severity of social attitudes in the continua "authoritarianism - democracy", "collectivism individualism", "altruism - egoism", "externality - internality". 
The sample of the study included 127 students of years 1 to 4 getting teacher education.

\section{Results}

\subsection{Determining the level of development of students' values during the period of their study at the university}

The first component of the values' structure is the main value attitude, which "represents a relative value for the subject of himself and the world around him." The value "Development of moral culture in the society" is most developed in the 1st year $(\mathrm{Mx}=4.2)$. The value "Well-being of loved ones" is of the highest priority for the 2nd year students $(\mathrm{Mx}=5.0)$. The values "Saving the environment" $(\mathrm{Mx}=3.8)$, "Life and safety of every person" $(\mathrm{Mx}=4.0)$ and "My well-being" $(\mathrm{Mx}=3.3)$ turn out to be the most developed to the 3rd year of study. "Strength and prosperity of the country" is most typical in the 2nd and 4th years $(\mathrm{Mx}=1.6)$ and the value "Economical and technological progress" is of importance for the 1 st and 4 th year students $(\mathrm{Mx}=1.9)$.

The second component of the values' structure is values as spheres of life, which are "functional modalities, through which a subject determines values.". The values "Family" $(\mathrm{Mx}=5.0)$, "Friendship" $(\mathrm{Mx}=3.6)$ and "Social life" $(\mathrm{Mx}=0.9)$ are of the greatest importance for the 1st year students. "Love" is important for the 2nd year students $(\mathrm{Mx}=$ 4.2). The values "Work / Study" $(\mathrm{Mx}=2.9)$ and "Rest" $(\mathrm{Mx}=3.0)$ are in the highest priority for the students of the 3rd year but "Personal health" is important in the 4th year $(\mathrm{Mx}=4.6)$.

The second component of the values' structure is values as life goals, which are traditionally "interpreted as basic motivational tendencies." The value "Self-development" turned out to be more important for the 1 st year $(\mathrm{Mx}=5.1)$. The values "Harmony of relations" ( $\mathrm{Mx}=4.2)$, "Desire for peace" $(\mathrm{Mx}=1.8)$, "Status" $(\mathrm{Mx}=1.7)$ are more pronounced among the 2nd year students. The value of "Financial well-being" is of the highest priority for the 4 th year students $(\mathrm{Mx}=4.0)$. The value "Diversity" is of the greatest importance for the 1st and 3rd year students $(\mathrm{Mx}=3.6)$ and "Dedication" is of equal importance for all the students regardless of the year of their study $(\mathrm{Mx}=2.4)$.

The forth component in the structure is primary functional values, which are understood as "basic functional modalities for determining the values". The values "Truth" $(\mathrm{Mx}=3.9)$, "Freedom" $(\mathrm{Mx}=4.2)$ and "Benefit" $(\mathrm{Mx}=2.9)$ are the most developed among the 1st year students. The values "Power (Strength)" $(\mathrm{Mx}=1.3)$ and "Justice" $(\mathrm{Mx}=4.2)$ are of the greatest importance for the 3rd year students. "Beauty" $(\mathrm{Mx}=2.4)$ and "Good" $(\mathrm{Mx}=4.5)$ are in the highest priority for the 4th year.

Analyzing the development of value orientations and value attitudes among the students during their study at a pedagogical university, we should note that democracy is most pronounced among the 1 st year students $(\mathrm{Mx}=-13.0)$ and collectivism in the 2 nd year $(\mathrm{Mx}$ $=4.7$ ). In turn, there is a sharp polarization of this continuum among the 3rd year students towards individualism $(\mathrm{Mx}=-7.0)$. The most altruistic are the 2 nd year students $(\mathrm{Mx}=-$ 11.9), but the 3rd year students are more selfish $(\mathrm{Mx}=1,3)$. Students of all courses are approximately equally internal $(\mathrm{Mx} \sim-14.4)$.

Students of the years 1, 2 and 4 are more focused on the value orientation of "Not I", and the 3rd year students on a neutral one. The obtained result may be explained with the fact that a student, entering a period of educational and professional crisis, seeks to occupy a clearer position in the group and in the professional community by developing his leadership qualities $[12,13]$. 


\subsection{Determining the dynamics of development of students' values during their study at the university.}

At the second stage of the empirical study, the obtained primary data were subjected to statistical processing. The dynamics of development of students' values throughout the entire period of their study at a pedagogical university was determined using the nonparametric H-criterion of Kruskal and Wallace (for two or more samples) [14]. For visual convenience, the results are presented as a table, which indicates only significant statistical differences (Table 1). There can be seen some dynamics in the level of development of the following values: "Saving the environment" $H=10.219$ at $\mathrm{p} \leq 0.05$; "Strength and prosperity of the country" $\mathrm{H}=7.637$ at $\mathrm{p} \leq 0.05$; "Development of moral culture in the society" $\mathrm{H}=7.895$ at $\mathrm{p} \leq 0.05$; "Family" $\mathrm{H}=7.064$ at $\mathrm{p} \leq 0.05$; "Friendship" $\mathrm{H}$ $=10.210$ at $\mathrm{p} \leq 0.05$; "Rest" $\mathrm{H}=9.678$ at $\mathrm{p} \leq 0.05$; "Truth" $\mathrm{H}=7.565$ at $\mathrm{p} \leq 0.05$. The analysis allows us to determine the direction of development and conclude that the dynamics of students' values during their study at the university is predominantly non-linear.

There is an absolute tendency towards a decrease in the level of development of the values "Truth" and "Friendship". Heterochronism with a tendency to increasing with some deceleration in the third year is found in the value "Strength and prosperity of the country". Heterochronism with a tendency to decreasing is found in the value "Development of moral culture in the society." Significance of the value of "Rest" increases from the year 1 to 3 with decreasing in the 4th year. The value of "Love" decreases in its significance in the years 1 to 3 with increasing in significance in the next year of study. A zigzag profile, i.e. absence of a certain regularity in development appears in the values "Saving the environment" and "Family".

Table 1 shows that there is dynamics in the level of development of the following value orientations and value attitudes: Authoritarianism / Democracy $\mathrm{H}=7.020$ at $\mathrm{p} \leq 0.05$; Collectivism / Individualism $H=11.280$ at $\mathrm{p} \leq 0.01$; Selfishness / Altruism $H=13.094$ at $\mathrm{p} \leq 0.01$; Directivity "Not-I" $\mathrm{H}=9.703$ at $\mathrm{p} \leq 0.05$; Neutral directivity $\mathrm{H}=7.189$ at $\mathrm{p} \leq 0.05$.

The analysis allows us to determine the direction of development and conclude that the dynamics of students' value orientations and value attitudes during their study at a university is predominantly non-linear. There is an absolute tendency towards changing their value orientations to decrease of democracy level.

Table 1. The dynamics of the development of students' values, value orientations and value attitudes during their study at a pedagogical university.

\begin{tabular}{|c|c|c|}
\hline & Chi-squared approximation & P-value \\
\hline Saving the environment & 10,219 &, $017^{*}$ \\
\hline Strength and prosperity of the country & 7,637 &, $044^{*}$ \\
\hline Development of moral culture in the society & 7,895 &, $048^{*}$ \\
\hline Family & 7,064 &, $050^{*}$ \\
\hline Friendship & 10,210 &, $017^{*}$ \\
\hline Rest & 9,678 &, $022^{*}$ \\
\hline Truth & 7,565 &, $046^{*}$ \\
\hline Authoritarianism / Democracy & 7,020 &, $050^{*}$ \\
\hline Collectivism / Individualism & 11,280 &, $010^{* *}$ \\
\hline Selfishness / Altruism & 13,094 &, $004^{* *}$ \\
\hline Direction "Not-I" & 9,703 &, $021^{*}$ \\
\hline Neutral focus & 7,189 &, $046^{*}$ \\
\hline Note. Hereinafter: significance level: $*-\mathrm{p} \leq 0,05 ; * *$ & $\mathrm{p} \leq 0,05$ & \\
\hline
\end{tabular}




\section{Discussion}

Planning the study we took into account the fact that methods of the last century are traditionally used to study values. However, theoretical analysis has shown that values are dynamic and change over time. Therefore, their study requires a modern methodological apparatus that allows to consider the problem of students' value orientations in a new perspective. So, we have proposed an improved method for studying values. We believe that the international scientific community will be interested in description of values and value orientations of Russian students for identifying new trends in their development.

Thus, the results of the empirical research allow us to make a conditional "value portrait" of a student in his development in each year of the university study:

For 1st year students, the following value relationships, value attitudes and orientations are significant: "Development of moral culture in the society", "Family", "Friendship", "Social life", "Self-development", "Truth", "Freedom", "Benefit", "Economical and technological progress". For 2nd year students, the most significant are "Well-being of loved ones", "Love", "Harmony of relationships", "Desire for peace" and "Status". For 3rd year students, the following value relationships, value attitudes and orientations are significant: "Saving the environment", "Life and safety of every person", "My well-being", "Work / Study", "Rest", "Power / Strength", "Justice", "Diversity". In the 4th year of study, students value most "Strength and prosperity of the country", "Personal health", "Beauty", "Good", "Economical and technical progress", "Financial well-being".

So, in the 1st course of a pedagogical university, the presence of both altruistic and selfish values can be defined. The obtained result might be explained by the fact that in the 1 st year the groups consist of students who have finished secondary schools of different types, different regions and different educational specialization. The 1st year students do not have a fully formed professional orientation on pedagogical activity, only their school identity is formed.

In the second year, there is a great focus on the "internal" orientation of the values, on their selfish tendencies. This can be explained by the age crisis of identity, the crisis of professionalization, which falls on the end of the 2nd year, as well as with the active period in the formation of student's worldview.

In the third year, there is a certain balance in the individual and social focus of values and value orientations, which is explained with the fact that the period of the formation of "educational and academic identity" ends and the "educational and professional identity" begins, and that is a natural process in professional identitying [15] during the university study, when professional values and motives, professional Self-concept and position, professional attitudes and beliefs, as well as ideas about the image of the teacher and about oneself as a teacher appear [16].

Based on these tendencies, we can conclude that in the fourth year of study there is a "social focus" of the pedagogical university students' values, which is manifested in greater democratization, collectivization, and humanization of life ideals. There is a gradual abandonment of "oneself" in favour of the "others", which means that due to school practice and studying professional disciplines, in the fourth year in the pedagogical university begins formation of students' own professional identity.

The obtained data agree with the general data available in the psychological and educational literature, where, in particular, is established that professional value orientations of students change from course to course. "By the end of training, they are approaching the indicators of professional value orientations of acting professionals. At the same time, a group of professional values as properties is distinguished, which remain practically unchanged throughout the entire course of students' training" [17]. Research 
also confirms the importance of organized activity in the development of value orientations of different kinds: authoritarianism, patriotism, spirituality, financial well-being, etc.

\section{Conclusion}

Thus, it is proved that the value system of students in a pedagogical university develops while getting professional education. This is explained, on the one hand, with the fact that in adolescence, in the context of personal self-determination, the system of worldview position is formed, which includes the subsystem of value orientations, made by including the student in the context of educational, academical and professional activities. The results of the research create the basis for further studying the features of teacher education values (dynamics of the formation of values starting since the early adolescence and in continuous teacher education, as well as multidisciplinary education). The results also help understand clearer the features of the genesis and transformations in the value system of educational subjects in the context of teacher education.

\section{References}

1. J. Caspersen, N. Frølich, European Journal of Education, 52 (1), 3-7 (2017)

2. N.M. Lebedeva, A.N. Tatarko, Psychology in Russia: State of the Art, 11 (3), 36-52 (2018)

3. B.S. Alishev, Scientific notes of the Pedagogical Institute of SSU named after N.G. Chernyshevsky. Series: Psychology. Pedagogy, 1, 3-26 (2011)

4. A.N. Kuteinikov, E.I. Ogareva, Fundamental research, 8-4, 989-993 (2014)

5. E.A. Omelchenko, G.S. Chesnokova, R.O. Agavelyan, Bulletin of the Novosibirsk State Pedagogical University, 1, 7-22 (2018)

6. R. Dwyer, Research Studies in Music Education, 37(1), 93-106 (2015)

7. R. Inglehart, W. Wetzel Modernization, Cultural Change and Democracy: The Sequence of Human Development (2011)

8. G. Czerniawski, European Journal of Education, 44(3), 421-440 (2009)

9. A.M. Khodyrev, T.V. Ledovskaya, N.E. Solynin, Problems of modern pedagogical education. Pedagogy and Psychology, 60 (3), 389-398 (2018)

10. D. Raufelder, L. Nitsche, S. Breitmeyer, S. Keßler, E. Herrmann, N. Regner, International Journal of Educational Research, 75, 31-44 (2016)

11. Values and social attitudes of modern students: structure and dynamics: collective monograph, ed. By B.S. Alishev (2010)

12. Y. Alioon, Ö. Delialioğlu, British Journal of Educational Technology, 50 (2), 655-668 (2019)

13. E.M. Solovieva, I.V. Zausenko, Modern problems of science and education, 3, 503503 (2015)

14. Y.N. Slepko, T.V. Ledovskaya, Data analysis and interpretation of psychological research' results (2013)

15. G.P. Yankov, Personality and Individual Differences, 131, 111-116 (2018)

16. M.C. Popa, Education and Self Development, 13 (3),16-24 (2018)

17. V.R. Bildanova, E.D. Grishanina, International Journal of Experimental Education, 61, 79-79 (2014). 